\title{
Indicadores de sustentabilidade: contribuições para construção de estratégias de desenvolvimento mais sustentável em agroecossistema de várzea
}

\section{Sustainability indicators: contributions to the construction of more sustainable development strategies in lowland agroecosystem}

Tayse Fernanda Amaral Silva - Mestre em Desenvolvimento Rural e Gestão de Empreendimentos Agroalimentares pelo Instituto Federal de Educação Ciência e Tecnologia do Pará (IFPA). E-mail: tayse.silva17@hotmail.com

Roberta de Fátima Rodrigues Coelho - Doutora em Ciências Agrárias pela Universidade Federal Rural da Amazônia (UFRA). Professora Titular do Instituto Federal de Educação, Ciência e Tecnologia (IFPA). E-mail: roberta.fatimacoelho@gmail.com

Romier da Paixão Sousa - Doutor em Estudios Medio Ambientales pela Universidad Pablo de Olavide. Professor Titular do Instituto Federal de Educação, Ciência e Tecnologia (IFPA). E-mail: romier.sousa.ifpa@gmail.com

\begin{abstract}
Resumo
Uma das principais discussões na atualidade refere-se ao fato de se repensar o modo de produzir alimentos, bem como a busca pelo desenvolvimento rural, a partir da perspectiva da sustentabilidade. Nesse contexto, surgem os indicadores de sustentabilidade, instrumentos que possibilitam uma avaliação mais ampla e multidimensional do desenvolvimento rural. Diante do exposto, o trabalho tem por objetivo apresentar uma síntese dos principais indicadores de sustentabilidade utilizados em agroecossistema de várzea, refletindo sobre os critérios empregados durante sua seleção, construção e resultados. A pesquisa foi realizada a partir de um levantamento bibliográfico e exploratório, em consulta de livros e periódicos científicos. Foram identificados doze indicadores compostos e um simples, observouse que a maioria são adaptações de trabalhos de referência, mas que sofreram alguma modificação em sua estrutura devido às características locais. Os trabalhos demonstraram que a efetividade do uso está intimamente ligada ao caráter participativo e à flexibilidade na construção.
\end{abstract}

\section{Palavras-chave}

Populações tradicionais. Ribeirinho. MESMIS. Amazônia.

\begin{abstract}
One of the main discussions today refers to the fact of rethinking the way of producing food, as well as the search for rural development, from the perspective of sustainability. In this context, sustainability indicators emerge, instruments that enable a broader and multidimensional assessment of rural development. Give in above, the work aims to show a synthesis of the main sustainability indicators used in the lowland agro-ecosystem of the Amazon, reflecting on the criteria used during their selection, construction and results. The research was carried out from a bibliographic and exploratory survey, in consultation with books and scientific journals. Twelve composite and one simple indicators were identified, it was observed that most are adaptations of reference works, but that has undergone some change in its structure, due to local characteristics. The studies demonstrated that the effectiveness of use is closely linked to the participatory character and flexibility in construction.
\end{abstract}

\section{Keywords}

Traditional populations. Riverside. MESMIS. Amazon. 


\section{INTRODUÇÃO}

O desenvolvimento foi tratado como sinônimo de crescimento econômico até a Conferência "Nosso Futuro Comum" em Estocolmo, em 1972, no qual os recursos naturais eram considerados inesgotáveis (DILGER; LANG; PEREIRA FILHO, 2016). No entanto, o reconhecimento de que essa perspectiva não contemplava outros aspectos, também importantes e fundamentais para a sustentabilidade do planeta, conduziu a sociedade a debates a respeito das perspectivas sobre o futuro da humanidade.

As discussões acerca das limitações do modelo de desenvolvimento até então adotado geraram diversos debates sobre a construção de ferramentas que indicassem um caminho para o desenvolvimento mais sustentável. Era necessário incorporar valores sociais e ambientais, nos quais a sustentabilidade precisava ser entendida dentro de uma perspectiva sistêmica (DAL SOGLIO, 2013) para, assim, ser alcançada, preservando a qualidade de vida e garantindo a conservação do ambiente, principalmente quando se referia aos modelos de produção agrícola.

Foi em meio a essa concepção que os indicadores de sustentabilidade emergiram, sendo criada uma diversidade desses. Contudo, apesar da expressiva quantidade, muitas vezes utilizá-los não foi um processo fácil (VIEIRA, 2019). Para tanto, alguns marcos metodológicos ou de referência surgiram para apoiar na mensuração do desenvolvimento sustentável (SANCHEZ; MATOS, 2012), especialmente em cenários mais complexos como a Amazônia, por ser uma região com uma multidiversidade de povos, identidades, singularidades, culturas e natureza original, além de sempre ter sido submetida a modelos desenvolvimentistas, os quais apresentavam tentativas de absorvê-la em uma lógica capitalista, por meio da exploração de suas riquezas (LOUREIRO, 2012).

Dentre suas várias particularidades, apresenta uma diversidade de agroecossistemas, chamando a atenção para um em especial por suas características singulares - as várzeas amazônicas. Esse ecossistema é habitado por povos e comunidades tradicionais que vivem e desenvolvem suas atividades produtivas, adaptando-as segundo o ritmo da natureza, constituindo-se em agroecossistemas familiares tradicionais (LIRA; CHAVES, 2016). Desse modo, pensar a perspectiva da sustentabilidade nesses territórios exige compreendê-la a partir de suas especificidades, potencialidades e fragilidades, além de buscar por ferramentas que apoiem no planejamento de políticas de desenvolvimento aliadas à realidade local.

O Marco para a Avaliação de Sistemas de Manejo Incorporando Indicadores de Sustentabilidade (MESMIS) é uma das ferramentas que segue 
esse desafio. Assim, frente à necessidade de compreender a produção familiar e as estratégias de reprodução social e produtiva em agroecossistemas de várzea, a utilização de indicadores de sustentabilidade, apoiada nessa ferramenta de análise, pode ser uma opção viável, já que, através deles, são obtidas informações relevantes e coerentes com a realidade analisada.

No entanto, surgem algumas indagações: será que os atuais indicadores utilizados em agroecossistemas familiares de várzea são suficientes para responder aos questionamentos propostos durante a avaliação da sustentabilidade, nas dimensões social, ambiental e técnico-econômica? Qual a contribuição dos indicadores de sustentabilidade nas discussões e estratégias acerca do desenvolvimento sustentável da região Amazônica? Para tentar responder a esses questionamentos, este artigo tem como objetivo apresentar uma síntese dos principais indicadores de sustentabilidade utilizados nesse agroecossistema, refletindo sobre os critérios empregados durante sua seleção, construção e resultados apresentados.

\section{METODOLOGIA}

A pesquisa foi de natureza qualitativa, a partir de um levantamento bibliográfico e exploratório, em consulta de livros e periódicos científicos sobre o uso de indicadores de sustentabilidade em agroecossistemas de várzea na Amazônia Brasileira. Para tal levantamento, foi realizada uma consulta na base de dados da plataforma de periódicos da Coordenação de Aperfeiçoamento de Pessoal de Nível Superior (CAPES), na qual, inicialmente, buscou-se por trabalhos que discutem o conceito, a origem e as características dos indicadores de sustentabilidade, como critérios de seleção e elaboração.

Ademais, optou-se por trabalhos que abordam o uso de indicadores, a partir da ferramenta MESMIS, desenvolvidos na região Norte. Sua escolha como ferramenta de avaliação se firma no fato de ser utilizada em diversas partes do mundo para avaliar agroecossistemas, tendo como foco sistemas familiares com ênfase em atividades de base ecológica (CÂNDIDO et al., 2015). Também apresenta características que justificam sua escolha, pois, além de promover agroecossistemas alternativos, possui estrutura flexível e adaptável aos diferentes níveis de informações, assim como se adapta a diferentes contextos locais e, principalmente, possibilita a construção participativa dos passos e indicadores (MASERA; ASTIER; LÓPEZ-RIDAURA, 2000).

Posteriormente, para identificação dos indicadores, optou-se como referência os períodos de 2010 a 2019, dos quais se destacaram quatro trabalhos. 
Para sua organização, utilizou-se uma planilha no programa Excel, contendo as seguintes informações: dimensão (ambiental, social e técnico-econômica), tipo e descrição dos indicadores. A partir dessas informações, os indicadores mais recorrentes de cada dimensão foram agrupados considerando os objetivos, sua característica (adaptados ou construídos) e sua forma de abordagem.

Diante do exposto, o artigo se organiza em quatro seções, das quais a primeira aborda o surgimento dos indicadores frente à necessidade de se repensar o desenvolvimento da sociedade em meio à crise ambiental. Partindo para uma discussão acerca da aplicação em agroecossistemas, a segunda seção caracterizase pelo uso de indicadores como ferramenta para avaliação destes, a partir da metodologia MESMIS, trazendo discussões que são importantes na elaboração ou escolha dos indicadores de sustentabilidade. Em seguida, reflete-se sobre a importância dos indicadores de sustentabilidade na construção de estratégias para o desenvolvimento da região Amazônica. Por fim, a quarta seção contempla o seu uso, no contexto da várzea, abordando os indicadores frequentemente utilizados.

\section{DA CRISE AMBIENTAL AO SURGIMENTO DOS INDICADORES DE SUSTENTABILIDADE}

O término da Segunda Guerra Mundial estabeleceu um novo mapa geopolítico mundial. Nesse cenário, os Estados Unidos passaram a regular a economia global, sendo responsável por ditar as diretrizes das políticas de desenvolvimento que, basicamente, se restringiram ao crescimento econômico (WEISHEIMER, 2013). Durante esse período, acompanhou-se o processo conhecido por "modernização da agricultura" em grande parte do planeta (DAL SOGLIO, 2013). Em meio a essa perspectiva, foram observadas mudanças quanto à dinâmica de uso dos recursos naturais, na qual a agricultura e o meio rural passaram a ser pauta de projetos de desenvolvimento.

Nesse processo, o modelo industrial-produtivista instalado para o desenvolvimento de países como o Brasil visava o incremento de insumos e tecnologias para aumentar a produtividade de produtos exportados. A chamada Revolução Verde, entretanto, trouxe como consequência a aceleração da degradação ambiental e social do espaço rural (ALTIERI, 2012), revelando a necessidade de se repensar o atual contexto de desenvolvimento, já que a agricultura perdeu sua conexão com a natureza e com a sociedade, passando a ser uma atividade de produção capitalista.

O rompimento da ideia de que os recursos naturais são infinitos e as crescentes dúvidas em relação ao futuro do meio ambiente marcaram a segunda 
metade do século XX, obrigando parte da humanidade a repensar suas ações acerca da exploração dos recursos naturais. É em meio a essa reflexão que a percepção e o conceito de desenvolvimento sustentável surgem.

Construído por meio de um longo processo histórico de reavaliação crítica, tem seu ponto de partida nas discussões internacionais, sendo precisamente a Conferência de Estocolmo, em 1972, a responsável pela base do conceito (GUIMARÃES; FEICHAS, 2009). Durante as décadas seguintes, ganhou força e tornou-se rapidamente usado em todos os seguimentos da sociedade, o que proporcionou o aprofundamento da discussão sobre seu real significado teórico e prático.

Apesar das diversas discussões, ainda não se tinha um consenso sobre o conceito do termo, existindo diversas abordagens, uma vez que suas várias interpretações ficaram a cargo das diferentes ideologias ou interesses (VAN BELLEN, 2004). No entanto, Vieira (2019) acrescenta que o conceito, imortalizado pela Comissão Brundtland, em 1987, contém a essência do que é e como se pode pensar o desenvolvimento sustentável, que seria garantir qualidade de vida para as gerações atuais sem comprometer as gerações futuras e atender suas próprias necessidades. Para Martins (2002), o conceito não está acabado, sendo considerado por ele como uma ideia-força, provocada tanto pelas demandas da sociedade quanto pelos problemas ambientais e, embora apresente diferentes abordagens, pressupõe considerar, também, as complexas relações entre a sociedade e a natureza.

Assim, partindo também para as perspectivas ambientais e sociais, motiva a sociedade a formular, implementar e avaliar as políticas públicas, estimulando a criação de novas formas de mensurá-lo (GUIMARÃES; FEICHAS, 2009). Todavia, Rabelo (2007) acrescenta que, em termos de efetividade, trabalhá-lo sob diferentes perspectivas demonstra-se mais complexo, exigindo ferramentas de avaliação que capturem essa complexidade, com abordagem sistêmica, considerando questões quantitativas, qualitativas, institucionais e históricas. É nesse contexto que os indicadores de sustentabilidade emergem, exercendo a função de advertir sobre possíveis riscos e tendências (KEMERICH et al., 2014), constituindo-se de um guia para que possam ser tomadas decisões a curto, médio ou longo prazo.

Os indicadores de sustentabilidade se referem a um instrumento de mensuração do grau de sustentabilidade do desenvolvimento, sendo responsável por fornecer informações multidimensionais (VIEIRA, 2019). Sua utilização tem por objetivo reunir e quantificar informações complexas, simplificando-as para o melhor entendimento e comunicação (HANAI; ESPÍNDOLA, 2011). 
Para Sarandón (2002), um indicador permite evidenciar uma tendência que não seria facilmente detectável de outra forma, tendo como principal característica a capacidade de agrupar e sintetizar um conjunto complexo de informações. Assim, são capazes de representar a percepção da realidade, permitindo entender os pontos limitantes e potencialidades que, de certa forma, passariam despercebidos.

A construção de indicadores de sustentabilidade se deu após a conferência Rio-92, com base nas recomendações da Agenda 21, que discorria acerca da necessidade de construí-los. Vários países aderiram às recomendações, tomando a iniciativa de elaborá-los para que contemplassem sua realidade e fossem capazes de nortear as tomadas de decisões. Nesse sentido, no Brasil, foram criados, pelo Instituto Brasileiro de Geografia e Estatística (IBGE), cerca de 50 indicadores de desenvolvimento sustentável (RABELO, 2007), com foco em temas como: população, saúde, educação, habitação, segurança, equidade, atmosfera, terra, oceano, mares e áreas costeiras, biodiversidade, saneamento, estrutura econômica, padrões de produção e consumo, estrutura e capacidade institucional (SILVA, 2008). Em 2015, o IBGE propôs novos indicadores, sendo que atualmente existem 63 que contemplam as dimensões sociais, ambientais, econômicas e institucionais (IBGE, 2015).

Apesar do número expressivo, a dificuldade quanto a sua utilização foi constante, visto que um dos pontos que restringe os trabalhos com indicadores é justamente a obtenção dos dados, tanto pelos aspectos de disponibilidade quanto de credibilidade, já que se utiliza de dados secundários e inviabiliza as pesquisas em esferas regionais ou globais. Essa dificuldade também estimulou o crescimento de aplicações de indicadores em práticas de desenvolvimento local (RABELO, 2007). Com esse objetivo, alguns marcos metodológicos ou de referência surgiram para apoiar na mensuração do grau de desenvolvimento local, especialmente para os aspectos voltados à realidade rural. Estes marcos tinham por objetivo melhorar o enfoque e esclarecer as medidas e os indicadores que deveriam ser utilizados, guiando todo o processo de análise da sustentabilidade da agricultura e, consequentemente, fortalecendo o desenvolvimento rural sustentável (SANCHEZ; MATOS, 2012).

Dentre os marcos metodológicos desenvolvidos para analisar a sustentabilidade de sistemas agrários, além do MESMIS, a principal ferramenta de discussão do trabalho, também são conhecidos o Metabolismo Social, Análise do Ciclo de Vida, Análise da Energia, Análises Custo-Benefício, Pegada Ecológica, Indicadores de Desenvolvimento Sustentável das Explorações Agrícolas (IDEA), Ferramenta de Avaliação de Impactos Ambientais e Indicadores de Sustentabilidade (AMBITEC) (CÂNDIDO et al., 2015; GORDIANO; VARGAS- 
ISLA, 2017; RODRIGUES et al., 2016). Apesar de existir um quantitativo de marcos metodológicos, cada um apresenta características específicas e particularidades de foco, que não cabem à discussão, uma vez que se tem como proposta apresentar o MESMIS como marco metodológico.

\section{INDICADORES DE SUSTENTABILIDADE COMO INSTRUMENTO PARA AVALIAÇÃO DE AGROECOSSISTEMAS: O USO DA FERRAMENTA MESMIS}

Na perspectiva dos agroecossistemas familiares, a utilização de indicadores de sustentabilidade é indispensável, pois somente dessa maneira poderá ser observado seu comportamento em diversas dimensões, o que possibilita a observação das novas propostas de sistemas de produção e organização a partir das avaliações de sustentabilidade, bem como o nível de transição agroecológica (VERONA, 2010). Partindo dessa premissa, os indicadores são bases para as avaliações a partir de propostas metodológicas e, considerando as complexidades e especificidades dos agroecossistemas de base familiar e ecológica, Masera, Astier e López-Ridaura (2000) apresentam o MESMIS como proposta metodológica para avaliar agroecossistemas, utilizando indicadores de sustentabilidade.

O MESMIS é uma ferramenta metodológica criada com o intuito de servir como ambiente de mediação do diálogo entre sujeito e realidade, o que acaba por promover agroecossistemas alternativos. Com foco em agricultores familiares e campesinos, atualmente é um método amplamente utilizado em diversas partes do mundo, conforme pode ser verificado por Astier et al. (2008), Masera, Astier e López-Ridaura (2000) e Zhirzhán e Ramiro (2013), e isso se deve, principalmente, à possibilidade de construção participativa nas etapas de seleção e/ou elaboração dos indicadores. No Brasil, mais especificamente na região norte, algumas experiências merecem destaque e podem ser observadas no Quadro 1.

Quadro 1 - Título e autores que discutem a avaliação da sustentabilidade na região Norte, através do método MESMIS

\begin{tabular}{|l|c|}
\hline \multicolumn{1}{|c|}{ TÍTULO } & AUTORES \\
\hline $\begin{array}{l}\text { Impactos do crédito produtivo nas noções locais de sustentabilidade } \\
\text { em agroecossistemas familiares no território sudeste do Pará }\end{array}$ & Silva (2008) \\
\hline $\begin{array}{l}\text { Diversificação produtiva em agroecossistemas familiares nos } \\
\text { Municípios de Santa Maria das Barreiras e Conceição do Araguaia, } \\
\text { Pará. }\end{array}$ & $\begin{array}{c}\text { Nogueira } \\
(2012)\end{array}$ \\
\hline $\begin{array}{l}\text { Avaliação de sustentabilidade em agroecossistemas de várzea da } \\
\text { agricultura camponesa no município de Igarapé-Miri (PA) }\end{array}$ & Oliveira (2015) \\
\hline
\end{tabular}




\begin{tabular}{|l|c|}
\hline $\begin{array}{l}\text { Sustentabilidade de agroecossistemas familiares em comunidade de } \\
\text { várzea localizada no município de Cametá, estado do Pará }\end{array}$ & $\begin{array}{c}\text { Resque e Silva } \\
(2017)\end{array}$ \\
\hline $\begin{array}{l}\text { Indicadores de sustentabilidade na compreensão de processo de } \\
\text { adaptação de agroecossistemas familiares no município de Curralinho, } \\
\text { PA. }\end{array}$ & $\begin{array}{c}\text { Carvalho e Silva } \\
(2017)\end{array}$ \\
\hline $\begin{array}{l}\text { Espaço amazônico e estado de sustentabilidade de lógicos familiares } \\
\text { de produção: adaptações e uso do MESMIS no caso do estado do } \\
\text { Pará }\end{array}$ & $\begin{array}{c}\text { Silva et al. } \\
(2017)\end{array}$ \\
\hline $\begin{array}{l}\text { Processos de manutenção da biodiversidade de agroecossistemas } \\
\text { familiares: estudo de caso na comunidade "Vila Braba", município de } \\
\text { Cametá, Baixo Tocantins-PA. }\end{array}$ & $\begin{array}{c}\text { Da Silva e Silva } \\
(2017)\end{array}$ \\
\hline $\begin{array}{l}\text { Evaluación de la sustentabilidad de los principios de la Red de } \\
\text { Agricultores Tradicionales del estado de Amazonas, Brasil }\end{array}$ & $\begin{array}{c}\text { Gordiano e } \\
\text { Vargas-Isla } \\
\text { (2017) }\end{array}$ \\
\hline
\end{tabular}

Fonte: elaborado pelos autores.

A ferramenta é passível de ser aplicada a diferentes sistemas e possibilita realizar uma leitura sistêmica do agroecossistema. Segundo Astier et al. (2012), ela estimula um processo de avaliação participativo e visão interdisciplinar, em que são envolvidos os atores sociais ligados à sustentabilidade do agroecossistema. Devido a essa característica, os agricultores cumprem papel essencial, uma vez que constroem, conjuntamente, o próprio conceito de sustentabilidade a partir dos atributos traduzidos pela ferramenta, que são: produtividade, resiliência, confiabilidade, estabilidade, adaptabilidade, equidade e autogestão (ASTIER et al., 2008). A respeito dos aspectos da avaliação, Cândido et al. (2015) acrescenta que um dos principais pontos a ser considerado no processo avaliativo é conhecer o conceito de sustentabilidade abordado pelo método, para evitar possíveis conflitos de entendimento dos grupos interessados.

O MESMIS, na sua estrutura, também apresenta características como flexibilidade e adaptabilidade a diferentes níveis de informação e capacitação técnica. A flexibilidade permite adaptações de acordo com as necessidades específicas dos agroecossistemas avaliados (VERONA, 2010). Outro ponto relevante é que este não se propõe somente a uma simples classificação da sustentabilidade dos sistemas, mas busca entender, de maneira geral, as limitações e possibilidades para a sustentabilidade, permitindo comparar os sistemas tanto transversalmente, ou seja, comparar um sistema alternativo com um de referência, quanto longitudinalmente, com observações das mudanças ao longo do tempo (ZHIRZHÁN; RAMIRO, 2013).

$\mathrm{Na}$ sua operacionalização, são considerados seis passos no processo avaliativo. O primeiro, busca caracterizar o sistema analisado, abordando os aspectos 
do manejo e seu contexto social, ambiental e econômico. Após essa etapa, são feitas as análises dos pontos críticos, identificando os fatores limitantes e favoráveis à sustentabilidade. Mais adiante, são determinados os critérios de diagnósticos associados aos atributos da sustentabilidade e, por conseguinte, os indicadores. $\mathrm{O}$ quarto passo relaciona-se à mediação e ao monitoramento dos indicadores, seguido da realização da integração e apresentação dos resultados. Por fim, no último passo são feitas as conclusões e recomendações, fechando o ciclo e, ao mesmo tempo, iniciando outro ao começar uma nova avaliação (SARANDÓN, 2002).

Embora a ferramenta contribua para a escolha dos indicadores utilizados, é preciso ter em mente que não existe uma lista universalutilizada para qualquer tipo de sistema, ou seja, assim como cada agroecossistema apresenta suas especificidades, faz-se necessário adequá-los e/ou construí-los conforme os objetivos que se propõem a serem estudados. Corroborando com essa questão, Ferraz (2003), Masera, Astier e López-Ridaura (2000) e Sarandón (2002) informam os requisitos importantes na elaboração ou escolha dos indicadores de sustentabilidade.

$\mathrm{O}$ indicador deve estar intimamente ligado à sustentabilidade, pois, somente assim, deve avaliar ou cobrir aspectos ecológicos, sociais, culturais e econômicos. Cabe aqui lembrar que a noção de sustentabilidade local não é préconcebida e deverá ser construída durante o processo de construção; assim, deve ser objetivo, consistente e significativo para a avaliação; ser de fácil medição e interpretação, baseando-se em informações facilmente disponíveis e de baixo custo; permitir integrar informações, ou seja, fornecer informações condensadas sobre os diversos aspectos da sustentabilidade; ser robusto, no sentido de refletir, realmente, o atributo que se quer avaliar; ser claro e centrar-se em aspectos práticos, a fim de facilitar a participação da população local no processo de mensuração; ser aplicável a um amplo número de ecossistemas, condições socioeconômicas e culturais; permitir avaliar mudanças ao longo do tempo e indicar tendências; permitir o cruzamento com outros indicadores.

No decorrer do processo avaliativo, alguns questionamentos também chamam a atenção e devem ser observados na construção e seleção dos indicadores. De acordo com Deponti et al. (2002), muitas informações são geradas, mas, posteriormente, não chegam a ser utilizadas. Assim, para se ter coerência com o propósito da avaliação, é necessário se perguntar: o que avaliar? Como avaliar? Por quanto tempo avaliar? Por que avaliar? De que elementos consta a avaliação? De que maneira serão expostos, integrados e aplicados os resultados da avaliação para o melhoramento do perfil dos sistemas analisados? Diante de todo o exposto, é notório compreender que, no processo de escolha e construção dos indicadores de sustentabilidade, deve-se levar em consideração 
todos os aspectos abordados anteriormente e defini-los em função das condições socioeconômicas e agroecológicas presentes em cada região.

\section{AIMPORTÂNCIA DOS INDICADORESDE SUSTENTABILIDADE NA CONSTRUÇÃO DE ESTRATÉGIAS PARA O DESENVOLVIMENTO DA AMAZÔNIA}

Uma região rica em biodiversidade, povos e tradições, a Amazônia, desde o início de sua ocupação, foi constituída em uma economia regulada na extração de produtos para benefícios de indústrias e centros mais desenvolvidos e, durante muito tempo, esteve à mercê de grandes projetos de desenvolvimento, que não estavam à altura de sua importância ecológica e social (MELLO, 2015).

Em meados do século XX, a região era caracterizada como um território isolado tanto no aspecto geográfico quanto econômico em relação às demais regiões do país, mas que se apresentava como um ambiente rico em possibilidades de ganho, a partir de sua exploração. Nesse sentido, diferentes políticas governamentais foram pensadas para transformar esse espaço em potencial, utilizando-se de técnicas que buscavam controlar a natureza, com o objetivo de desenvolvê-la economicamente (CARVALHO; SILVA, 2017). Contudo, o que se percebeu foi uma série de problemas socioeconômicos e ambientais, devido às tentativas de incrementar atividades não compatíveis com as características locais.

A política de desenvolvimento, desenhada na década de 1970 até o final dos anos 1990, tinha como ideia um modelo de uso intensivo da terra e dos recursos, com reflexos do que se pensava ainda nos anos de 1950 pelos governos militares, como um espaço vazio e economicamente desintegrado do restante do país, em que a natureza era vista como improdutiva e que precisava ser substituída por atividades de exploração rentáveis para o mercado (ESTERCI; SCHWEICKARDT, 2010). Nesse contexto, o domínio da terra e o uso dos recursos naturais precisavam ser homogeneizados, sendo necessário substituir ou superar as formas construídas localmente.

O fato é que, nesse momento, o Estado ignorou a diversidade de modos de vida presentes na região, negando as formas tradicionais de apropriação e uso do espaço adotadas pelos habitantes locais, homogeneizando a forma de domínio sobre a terra, visando integrar a Amazônia à economia nacional (BEZERRA, 2011; ESTERCI; SCHWEICKARDT, 2010). Ainda na década de 1970, grandes empresas tiveram apoio para desenvolver atividades voltadas para a agropecuária e, como consequência, desenvolver o setor madeireiro, visto como única via de dominar o ambiente (LOUREIRO, 2012). Dessa maneira, ainda segundo a autora, 
buscou-se por criar um setor agropecuário moderno com o intuito de substituir as famílias extrativistas e criar um ideal agrícola para os agricultores camponeses locais.

Durante a década seguinte, as políticas públicas para o plano de desenvolvimento da região continuaram sob a lógica progressista, criando estratégias para favorecer os grandes projetos que se articulavam em atividades dos setores hidrelétrico, agropecuário e de mineração, considerados estratégicos para a economia da região, através de subsídios e incentivos fiscais a grandes grupos privados (BEZERRA, 2011). No entanto, essas políticas, pensadas sob as mesmas perspectivas anteriores, também repercutiram negativamente nas dinâmicas socioambientais da região.

Em meio a esse contexto, ainda nos anos de 1980, a ideia desse modelo começou a dar sinais de fracasso, devido a diversos problemas sociais e ambientais, nos quais os desflorestamentos, a migração e os conflitos por posse de terra foram pautas de discussões de ambientalistas e movimentos sociais, surgindo, assim, uma preocupação com o futuro socioambiental amazônico. É em meio a essas discussões, no final desta década e início dos anos de 1990, que começam a se desenvolver novas concepções de desenvolvimento regional (LOUREIRO, 2012), sendo considerado, segundo Silva et al. (2017), como marco da nova relação do Estado com essa concepção, a criação de Projetos de Assentamentos (PAs) e reconhecimento de terras indígenas e quilombolas e a criação de Unidades de Conservação (UCs).

$\mathrm{O}$ atual contexto de desenvolvimento rural aparentemente aponta para certos avanços. Para Schroder (2010), pensar em estratégia para este processo requer avançar em ações de apoio aos agricultores familiares e às comunidades tradicionais, visto que estes sujeitos, frente às reproduções das suas próprias condições de existência, constroem sistemas produtivos adaptados às características do ecossistema local, com práticas, saberes específicos e sistemas mais sustentáveis do ponto de vista ambiental. Ainda segundo o autor, apesar de já se pensar em políticas destinadas aos interesses desses povos, ainda é preciso avançar em articulações que envolvam a diversidade existente, principalmente quando se trata da complexidade dos sistemas produtivos.

Dessa forma, para se construir uma nova perspectiva de desenvolvimento, é preciso fundamentar-se em cinco pilares: (a) o respeito pela identidade dos povos e diferença cultural, (b) o aproveitamento de práticas sociais e saberes seculares estabelecidos pelos seus habitantes, (c) o respeito pela natureza, transformando-a em aliada, (d) aproveitar a biodiversidade, no sentido de construir uma vida mais solidária e (e) desenvolver e investir cada vez mais em ciência, especialmente na ciência aplicada, direcionando-a para os interesses regionais (LOUREIRO, 2012). 
Diante desse histórico de tentativas de desenvolvimento da região, notase que as políticas se centravam em interesses econômicos, desfavoráveis às populações locais, sendo evidente a dificuldade de diálogo com estes sujeitos. Logo, pautar-se em estratégias para o desenvolvimento sustentável exigia buscar ferramentas que apoiassem as tomadas de decisões e o planejamento de políticas públicas coerentes para determinado meio, a fim de promover a qualidade de vida dos povos que vivem nessa região, bem como o equilíbrio na gestão dos recursos naturais. Assim, os indicadores de sustentabilidade trazem esse desafio de subsidiar os processos de planejamento e tomadas de decisões.

Os indicadores de sustentabilidade tornam-se úteis nas tomadas de decisões, favorecendo o planejamento de ações, por meio do fornecimento de informações nas múltiplas dimensões. Seu uso pressupõe a chance de elaborar políticas em todos os níveis, coerentes com a realidade local, além de serem norteadores para que se mantenha o monitoramento em direção ao desenvolvimento sustentável (SOUZA et al., 2016). Com os resultados das avaliações é possível conscientizar a população dos reais problemas existentes, assim como poder muni-los com documentos que poderão ser usados perante órgão competente para a formulação de políticas públicas que venham resolver estas demandas.

\section{PRINCIPAIS INDICADORES DE SUSTENTABILIDADE UTILIZADOS NO CONTEXTO DA VÁRZEA NA AMAZÔNIA BRASILEIRA}

Um dos primeiros passos na avaliação por meio de indicadores é compreender o contexto no qual os sujeitos estão inseridos, bem como as características do agroecossistema a ser estudado. Nesse sentido, a várzea é retratada como um ecossistema que constitui áreas que estão em constante inundação, sofrendo influência da maré, além de ser considerada como um ambiente rico em termos de produtividade biológica, biodiversidade e recursos naturais, especialmente pelo alto teor de nutrientes renovados periodicamente em seus solos (LIMA et al., 2001).

Nesses ecossistemas, são identificados povos tradicionais - ribeirinhosque possuem estreita relação com os rios, vivendo em pequenas comunidades, em sua maioria, à beira dos rios, igarapés e lagos que compõem o vasto e complexo estuário amazônico, mas que, por estarem nesse espaço, modificamno, desenvolvendo estratégias adaptativas peculiares (NODA; NODA, 2003) e adaptando seu modo de produzir e reproduzir segundo o ciclo da natureza. 
Os ribeirinhos possuem sistemas produtivos trabalhados sobre a lógica da várzea e são considerados, segundo Pereira e Diegues (2010), como extrativistas e agricultores, uma vez que o homem da várzea apresenta uma diversidade de saberes e conhecimentos, buscando por estratégias de diversificação da sua produção, manejando um conjunto de atividades que envolvem a extração dos produtos da floresta, pesca, caça, passando a desenvolver práticas de plantio e colheita de produtos alimentícios e até a criação de pequenos animais.

Um dos principais desafios no processo avaliativo de agroecossistemas incorporando indicadores é que estes sejam eficientes, no sentido de gerar informações que, posteriormente, possam ser utilizadas, bem como obtê-los condizentes com a realidade estudada, o que denota um certo cuidado ao escolhêlos para tal função (MASERA; ASTIER; LÓPEZ-RIDAURA, 2000). Para Carvalho e Silva (2017), na avaliação voltada para o agroecossistema de várzea, é preciso considerar a existência de distintas lógicas de produção, em decorrência das iniciativas das famílias frente às inconstâncias do contexto socioeconômico no qual se encontram.

Diante desse entendimento, Silva et al. (2017) reafirmam essa questão ao comparar experiências práticas de aplicação da ferramenta MESMIS em distintas realidades amazônicas do estado do Pará e, diante desta análise, identificaram que uma das principais dificuldades na avaliação tem relação com o processo de adaptação dos indicadores de sustentabilidade aos distintos territórios, marcando uma dificuldade prática, que busca integralizar e representar, de forma fiel, o atual estado de sustentabilidade. Por outro lado, o autor também acrescenta que, nesse processo, o ponto chave para garantir maior grau de precisão é ter a participação ativa do pesquisador na realidade estudada, bem como a garantia do protagonismo dos sujeitos locais na maioria dos passos propostos pela ferramenta.

Assim, a respeito das avaliações realizadas no contexto da várzea, os trabalhos de Carvalho e Silva (2017), Da Silva e Silva (2017), Resque e Silva (2017) e Silva et al. (2017) se destacaram, de modo que se compilou nos quadros 2, 3 e 4 os indicadores de sustentabilidade mais abordados nesse agroecossistema para a avaliação multidimensional.

$\mathrm{Na}$ dimensão ambiental (Quadro 2), quatro indicadores compostos foram observados. Estes indicadores buscaram avaliar como ocorre a gestão dos recursos naturais disponíveis, de modo a dialogar com a sua garantia de existência em longo prazo. 
Quadro 2 - Indicadores de sustentabilidade ambiental utilizados em agroecossistema de várzea a partir da ferramenta MESMIS

\begin{tabular}{|c|c|}
\hline $\begin{array}{l}\text { INDICADORES DE SUSTENTABILIDADE } \\
\text { AMBIENTAL }\end{array}$ & $\begin{array}{l}\text { DESCRIÇÃO DOS } \\
\text { INDICADORES }\end{array}$ \\
\hline Manutenção da biodiversidade natural (ADN) & \multirow{3}{*}{$\begin{array}{c}\text { Avaliam a fauna e a flora, } \\
\text { analisando a relação estabelecida } \\
\text { entre os sujeitos e a diversidade } \\
\text { local }\end{array}$} \\
\hline Manutenção da vegetação natural & \\
\hline Diversidade de espécies utilizadas & \\
\hline Conservação do recurso pesquei & \multirow{4}{*}{$\begin{array}{l}\text { Os indicadores têm como } \\
\text { princípio identificar como o tipo } \\
\text { de pesca realizado vai influenciar } \\
\text { na conservação do recurso } \\
\text { pesqueiro }\end{array}$} \\
\hline Tipo de pesca realizada & \\
\hline Redução na quantidade e qualidade & \\
\hline Práticas Conservacionistas & \\
\hline osta ao mei & \multirow{6}{*}{$\begin{array}{c}\text { Avaliam as consequências } \\
\text { causadas ao meio ambiente } \\
\text { decorrentes do tipo de manejo } \\
\text { desenvolvido }\end{array}$} \\
\hline Qualidac & \\
\hline Erosão visível & \\
\hline Presença de pragas e doenças & \\
\hline Qualidade da água & \\
\hline Presença de lixo & \\
\hline Manutenção da diversidade produtiva (ADE) & \multirow{3}{*}{$\begin{array}{l}\text { Buscam avaliar a utilização } \\
\text { de espécies e de atividades de } \\
\text { produção agrícola }\end{array}$} \\
\hline Diversidade de espécie/atividade & \\
\hline Diversidade de atividade produtiva & \\
\hline
\end{tabular}

Fonte: elaborado pelos autores com base em Carvalho e Silva (2017), Da Silva e Silva (2017), Resque e Silva (2017) e Silva et al. (2017).

No Quadro 3, são notados cinco indicadores usados para avaliar essa dimensão, sendo que, destes, apenas o Endividamento Familiar (TEVID) é um indicador simples. Os indicadores técnico-econômicos são responsáveis por avaliar a eficiência produtiva do agroecossistema, com observações no manejo aplicado, o rendimento obtido e as relações que são estabelecidas ao longo da produção.

Quadro 3 - Indicadores de sustentabilidade técnico-econômico utilizados em agroecossistema de várzea a partir da ferramenta MESMIS

\begin{tabular}{|c|c|}
\hline $\begin{array}{c}\text { INDICADORES DE SUSTENTABILIDADE } \\
\text { TÉCNICO - ECONÔMICO }\end{array}$ & $\begin{array}{c}\text { DESCRIÇÃO DOS } \\
\text { INDICADORES }\end{array}$ \\
\cline { 1 - 1 } Desempenho da economia familiar (TECON) & \multicolumn{1}{|c|}{$\begin{array}{c}\text { Permitem observar as estratégias } \\
\text { utilizadas pela família para } \\
\text { obtenção de renda }\end{array}$} \\
\cline { 1 - 1 } Renda familiar per capita (Salário-mínimo/mês) & \\
\cline { 1 - 1 } Importância das atividades produtivas & \\
\cline { 1 - 1 } Importância da venda de mão de obra & \\
\cline { 1 - 1 } Tamanho do patrimônio familiar &
\end{tabular}




\begin{tabular}{|c|c|}
\hline Endividamento Familiar (TEVID) & $\begin{array}{c}\text { Avalia o grau de endividamento } \\
\text { da família } \\
\end{array}$ \\
\hline Eficiência do Manejo (TEFIC) & \multirow{8}{*}{$\begin{array}{c}\text { Caracterizam-se por avaliar o } \\
\text { rendimento obtido a partir do } \\
\text { manejo no sistema, levando em } \\
\text { consideração aspectos como o } \\
\text { tipo e quantidade de insumos } \\
\text { empregados }\end{array}$} \\
\hline Rendimento físico médio & \\
\hline Perda de rendimento físico & \\
\hline Integração das atividades & \\
\hline Sazonalidade de produção & \\
\hline Domínio do manejo & \\
\hline Dependência de insumos externos & \\
\hline Diversidade de atividades & \\
\hline Possibilidade de diversificação (TEDIVERS) & \multirow{6}{*}{$\begin{array}{l}\text { São indicadores importantes } \\
\text { para identificar elementos que } \\
\text { possibilitam diversificar as } \\
\text { atividades realizadas dentro do } \\
\text { agroecossistema }\end{array}$} \\
\hline Diversidade de linhas de crédito disponíveis & \\
\hline Diversidade de iniciativas de capacitação & \\
\hline Diversificação atual & \\
\hline Vontade de manter o sistema diversificado & \\
\hline Manutenção da diversidade natural & \\
\hline Estratégias de comercialização (TECM) & \multirow{8}{*}{$\begin{array}{c}\text { Avaliam as estratégias de } \\
\text { comercialização desempenhadas } \\
\text { pelos sujeitos envolvidos, } \\
\text { direcionado tanto para as } \\
\text { relações estabelecidas quanto } \\
\text { para a forma que o produto é } \\
\text { comercializado }\end{array}$} \\
\hline Atores envolvidos no processo & \\
\hline Tipo de produto comercializado & \\
\hline Estrutura para industrialização da produção & \\
\hline Conhecimento de mercado & \\
\hline Canais de comercialização & \\
\hline Sazonalidade & \\
\hline Associativismo & \\
\hline
\end{tabular}

Fonte: elaborado pelos autores com base em Carvalho e Silva (2017), Da Silva e Silva (2017), Resque e Silva (2017) e Silva et al. (2017).

Já na dimensão social (Quadro 4), somaram-se também quatro indicadores compostos usados para avaliar a sustentabilidade. São indicadores importantes, pois refletem aspectos da qualidade de vida familiar e como os elementos que envolvem os sujeitos podem influenciar na estrutura familiar. 
Quadro 4 - Indicadores de sustentabilidade social utilizados em agroecossistema de várzea, utilizando a ferramenta MESMIS

\begin{tabular}{|c|c|}
\hline $\begin{array}{c}\text { INDICADORES DE } \\
\text { SUSTENTABILIDADE SOCIAL }\end{array}$ & DESCRIÇÃO DOS INDICADORES \\
\hline Qualidade de vida (SQV) & \multirow{9}{*}{$\begin{array}{l}\text { São responsáveis por avaliar a } \\
\text { disponibilidade e a qualidade dos serviços } \\
\text { públicos básicos que devem ser ofertados, } \\
\text { fundamentais para que se tenha qualidade } \\
\text { de vida }\end{array}$} \\
\hline Acesso a serviços públicos de saúde & \\
\hline $\begin{array}{l}\text { Acesso a serviços públicos de } \\
\text { saneamento básico }\end{array}$ & \\
\hline Acesso a serviços públicos de segurança & \\
\hline Serviços públicos de educação & \\
\hline Situação da saúde familiar & \\
\hline Situação da escolaridade familiar & \\
\hline $\begin{array}{l}\text { Acesso à política de regularização } \\
\text { fundiária }\end{array}$ & \\
\hline Violência social na comunidade & \\
\hline Nível de organização (SORG) & \multirow{5}{*}{$\begin{array}{l}\text { Consideram o nível de organização da } \\
\text { comunidade, considerando as relações das } \\
\text { famílias com as instituições presentes }\end{array}$} \\
\hline Participação em organizações & \\
\hline Participação nas decisões coletivas & \\
\hline Diálogo com a ATER & \\
\hline Acesso a informações & \\
\hline $\begin{array}{l}\text { Capacidade de trabalho familiar } \\
\text { (STRAB) }\end{array}$ & \multirow{5}{*}{$\begin{array}{c}\text { Avalia o envolvimento familiar no trabalho, } \\
\text { relacionando seus esforços nas atividades } \\
\text { demandadas dentro da propriedade. Para } \\
\text { tanto, é observada a capacidade de cobrir } \\
\text { essa demanda, seja ela pela mão de obra } \\
\text { familiar ou contratada }\end{array}$} \\
\hline Contratação de mão de obra & \\
\hline Trabalho fora do lote & \\
\hline Descanso e lazer & \\
\hline Capacidade de cobrir demanda interna & \\
\hline
\end{tabular}

Fonte: elaborado pelos autores com base em Carvalho e Silva (2017), Da Silva e Silva (2017), Resque e Silva (2017) e Silva et al. (2017).

A partir do levantamento dos trabalhos, observa-se que a maioria dos indicadores é adaptado, oriunda de trabalhos de referência, mas que sofreu alguma modificação em sua estrutura devido às características locais, o que, de certo modo, também reflete nos parâmetros usados para auxiliar na sua mensuração. Salienta-se, ainda, a presença de indicadores elaborados especificamente para a realidade estudada, construídos a partir da percepção em campo em conjunto com os atores locais, tais como: conservação do recurso pesqueiro (ARP) e estratégias de comercialização (TECM). Em síntese, realizar o levantamento desses indicadores fortalece no processo de construção e adaptação de novos.

Ademais, os referidos autores, Carvalho e Silva (2017), Resque e Silva (2017), Silva et al. (2017), abordam a importância da inserção do pesquisador no espaço onde se realizará o estudo, principalmente durante o processo de 
adaptação dos indicadores. A participação dos sujeitos locais também apresentou níveis significativos, visto que uma das etapas iniciais desse processo depende do levantamento dos pontos críticos e estratégicos, pois estabelecê-los junto aos interessados poderá revelar um panorama ambiental e socioeconômico específico que aparenta afetar a sustentabilidade.

\section{CONSIDERAÇÕES FINAIS}

Ainda que existam muitos desafios na utilização de indicadores para a Amazônia, estes desempenham um papel importante no planejamento de ações, avaliando as ações humanas sobre as condições do ecossistema e bem-estar socioeconômico da população, pois, quando estabelecem uma eficaz conexão de comunicação das informações e mensuração mais próxima da realidade estudada, contribuem na tomada de decisão para a construção de estratégias que fortalecerão o desenvolvimento local, principalmente de uma região tão complexa, com diferentes realidades, agroecossistemas, usos e gestão dos recursos.

Acerca dos indicadores de sustentabilidade utilizados nos agroecossistemas de várzea, por meio da ferramenta MESMIS, ao todo, foram contabilizados doze indicadores compostos e um simples. São indicadores que, de certo modo, não podem ser excluídos durante uma análise multidimensional. Contudo, ressalta-se a importância de se entender a lógica de produção e os aspectos que conferem fragilidades ou potencialidades para a sustentabilidade dos agroecossistemas, já que tais informações contribuem para a seleção que melhor caracterizarão a realidade estudada.

Também é interessante mencionar que grande parte são adaptados de trabalhos de referência, com alterações na estrutura, em decorrência das características locais. Logo, os trabalhos demonstraram que a efetividade na adaptação e aplicação está intimamente ligada à flexibilidade na definição dos indicadores e ao caráter participativo tanto pela inserção do pesquisador no espaço quanto pela presença constante dos sujeitos locais.

A respeito dos seus objetivos, de maneira geral, buscaram compreender como as decisões tomadas dentro do agroecossistema têm influência na qualidade de vida, ou seja, como o manejo dentro do agroecossistema pode afetar as famílias nos aspectos ambientais, técnico-econômico e social.

\section{REFERÊNCIAS}

ALTIERI, M. Agroecologia: bases científicas para uma agricultura sustentável. Rev. Ampl. São Paulo: Expressão Popular; Rio de Janeiro: AS-PTA, 2012. 379 p. 
ASTIER, M. et al. Evaluación de sustentabilidad un enfoque dinámico y multidimensional. Catarroja, Valencia: SEAE, 2008.

ASTIER, M. et al. Assessing the sustainability of small farmer natural resource management systems. a critical analysis of the MESMIS Program (1995-2010). Ecology and Society, [s. l.], v. 17, n. 3, p. 1-20, 2012.

BEZERRA, N. R. C. A Amazônia e os novos paradigmas de desenvolvimento rural: uma breve reflexão teórica. Revista Brasileira de Agroecologia, Dois Vizinhos, v. 6, p. 40-54, 2011.

CÂNDIDO, G. D. A. et al. Avaliação da sustentabilidade de unidades de produção agroecológicas: um estudo comparativo dos métodos IDEA e MESMIS. Ambiente \& Sociedade, São Paulo, v. 18, n. 3, p. 99-120, set. 2015. Disponível em: http://www.scielo.br/scielo.php?script=sci_arttext\&pid=S1414 753X2015000300007\&lng=en\&nrm=iso. Acesso em: 27 mar. 2019.

CARVALHO, J. P. L.; SILVA, L. M. S. Indicadores de sustentabilidade na compreensão de processo de adaptação de agroecossistemas familiares.

Agricultura Familiar: pesquisa, formação e desenvolvimento, Belém, v. 11, n. 1, p. 87-102, jul./dez. 2017.

DA SILVA, L. P.; SILVA, L. M. S. Processos de manutenção da biodiversidade de agroecossistemas familiares: estudo de caso na comunidade "Vila Braba", município de Cametá, Baixo Tocantins-PA. Agricultura Familiar: pesquisa, formação e desenvolvimento, Belém, v. 11, n. 2, p. 71-84, jul./dez. 2017.

DAL SOGLIO, F. K. Desenvolvimento, agricultura e agroecologia: qual a ligação. In: GUERRA, G. A. D.; WAQUIL, P. D. (org.). Desenvolvimento rural sustentável no Norte e Sul do Brasil. Belém: Paka-Tatu, 2013. p. 197-226.

DEPONTI, C. M. et al. Estratégia para construção de indicadores para avaliação da sustentabilidade e monitoramento de sistemas. Agroecologia e Desenvolvimento Rural Sustentável, Porto Alegre, v. 3, p. 44-52, out./dez. 2002.

DILGER, G.; LANG, M.; PEREIRA FILHO, J. Descolonizar o imaginário: debates sobre o pós-extrativismo e alternativas ao desenvolvimento. São Paulo: Fundação Rosa Luxemburgo, 2016. 472 p.

ESTERCI, N.; SCHWEICKARDT, K. H. S. C. Territórios amazônicos de reforma agrária e de conservação da natureza. Bol. Mus. Para. Emílio Goeldi. Cienc. Hum, Belém, v. 5, p. 59-77, jan./ abr. 2010. Disponível em: http:/ /www.scielo.br/scielo.php?script=sci_arttext\&pid=S19818122201000010 0006\&lng=en\&nrm=iso. Acesso em: 30 de out. 2019. 
FERRAZ, J. M. G. As Dimensões da sustentabilidade e seus indicadores. In: MARQUES, J. F.; SKORUPA, L. A.; FERRAZ, J. M. G. (Ed.). Indicadores de sustentabilidade em agroecossistemas. Jaguariúna: Embrapa Meio Ambiente, 2003. p. 15-35.

GORDIANO, J. B. A.; VARGAS-ISLA, R. Evaluación de la sustentabilidad de los principios de la Red de Agricultores Tradicionales del estado de Amazonas, Brasil. Agricultura Familiar: pesquisa, formação e desenvolvimento, Belém, v. 11, n. 1, p. 119-138, jul./dez. 2017.

GUIMARÃES, R. P.; FEICHAS, S. A. Q. Desafios na construção de indicadores de sustentabilidade. Ambiente $\&$ Sociedade, Campinas, v. 12, n. 2, p. 307-323, jul./dez. 2009. Disponível em: http:/ / www.scielo.br/scielo.php?script=sci_arttext\&pid=S1414753X2009000200007\&lng=en\&nrm=iso. Acesso em: 27 fev. 2019.

HANAI, F. Y.; ESPÍNDOLA, E. L. G. Indicadores de sustentabilidade: conceitos, tipologias e aplicação ao contexto do desenvolvimento turístico local. Revista de Gestão Social e Ambiental, São Paulo, v. 5, n. 3, p. 135-149, set./ dez. 2011.

IBGE. Indicadores de desenvolvimento sustentável: Brasil. Rio de Janeiro: IBGE, 2015. 352 p.

KEMERICH, P. D. C. et al. Indicadores de sustentabilidade ambiental: métodos e aplicações. Revista Monografias Ambientais, Santa Maria, v. 13, n. 4, p. 3718-3722, 2014.

LIMA, R. R. et al. Várzeas flúvio-marinhas da Amazônia brasileira: características e possibilidades agropecuárias. 2. ed. Belém: 2001. 341 p.

LIRA, T. D. M.; CHAVES, M. D. P. S. R. Comunidades ribeirinhas na Amazônia: organização sociocultural e política. Interações, Campo Grande, MS, v. 17, n. 1, p. 66-76, 2016.

LOUREIRO, V. R. A Amazônia no século 21: novas formas de desenvolvimento. Revista Direito GV, São Paulo, v. 8, n. 2, p. 527-552, jul./dez. 2012. Disponível em: http://repositorio.ufpa.br/jspui/handle/2011/10101. Acesso em: 01 abr. 2019.

MARTINS, S. R. Desenvolvendo a sustentabilidade. In: CONGRESSO BRASILEIRO DE OLERICULTURA, 42.; CONGRESSO LATINOAMERICANO DE HORTICULTURA, 11., 2002, Uberlândia. Anais [...]. Uberlândia: CBO, 2002. p. 1-12. 


\section{MASERA, O.; ASTIER, M.; LÓPEZ-RIDAURA, S. Sustentabilidad y} manejo de recursos naturales: el marco de evalución MESMIS. Michoacán, México: GIRA: Instituto de Ecología, 2000. 101 p.

MELLO, A. F. Dilemas e desafios do desenvolvimento sustentável da Amazônia: o caso brasileiro. Revista Crítica de Ciências Sociais, Coimbra, n. 107, p. 91-108, 2015.

NODA, H.; NODA, S. N. Agricultura familiar tradicional e conservação da sócio-biodiversidade amazônica. Interações, Campo Grande, v. 4, n. 6, p. 55-66, mar. 2016. Disponível em: http://www.interacoes.ucdb.br/article/ view/559. Acesso em: 02 jan. 2020.

NOGUEIRA, A. C. N. Diversificação produtiva em agroecossistemas familiares nos Municípios de Santa Maria das Barreiras e Conceição do Araguaia, Pará. 2012. Dissertação (Mestrado em Agriculturas Familiares e Desenvolvimento Sustentável) - Programa de Pós-Graduação em Agriculturas Familiares e Desenvolvimento Sustentável, Universidade Federal do Pará, Belém, 2012.

OLIVEIRA, A. E. M. Avaliação de Sustentabilidade em Agroecossistemas de Várzea da Agricultura Camponesa no Município de Igarapé-Miri (PA). 2015. Dissertação (Mestrado em Desenvolvimento Rural e Gestão de Empreendimentos Agroalimentares) - Programa de Pós-Graduação em Desenvolvimento Rural e Gestão de Empreendimentos Agroalimentares, Instituto Federal de Educação, Ciência e Tecnologia do Pará, Castanhal, 2015.

PEREIRA, B. E.; DIEGUES, A. C. Conhecimento de populações tradicionais como possibilidade de conservação da natureza: uma reflexão sobre a perspectiva da etnoconservação. Desenvolvimento e Meio Ambiente, Curitiba, n. 22, p. 37-50, jul./dez, 2010.

RABELO, L. S. Indicadores de sustentabilidade: uma sequência metodológica para a mensuração do processo ao desenvolvimento sustentável. 2007. Dissertação (Mestrado em Desenvolvimento e Meio Ambiente) - Programa de Pós-Graduação em Desenvolvimento e Meio Ambiente, Universidade Federal do Ceará, Fortaleza, 2007.

RESQUE, A. G. L.; SILVA, L. M. S. Sustentabilidade de agroecossistemas familiares em comunidade de várzea localizada no município de Cametá, estado do Pará. Agricultura Familiar: pesquisa, formação e desenvolvimento, Belém, v. 11, n. 1, p. 103-118, jul./dez. 2017. 


\section{RODRIGUES, G. S. R. et al. Ferramenta de avaliação de impacto} ambiental e indicadores de sustentabilidade na Embrapa. Jaguariúna: Embrapa, 2016.

SANCHEZ, G. F.; MATOS, M. M. Marcos Metodológicos para Sistematização de Indicadores de Sustentabilidade da Agricultura. (SYN)THESIS, Rio de Janeiro, v. 5, n. 2, p. 255-266, 2012.

SARANDÓN, S. J. (ed.). Agroecología: el camino hacia una agricultura sustentable. Buenos Aires: E.C.A. Ed. Científicas Americanas, 2002. 560 p. SCHRODER, M. Desenvolvimento rural, meio ambiente e políticas públicas: os caminhos do fortalecimento da agricultura familiar na Amazônia brasileira. PRACS: revista eletrônica de humanidades do curso de ciências sociais da UNIFAP, Macapá, v. 3, n. 3, p. 53-67, 2010.

\section{SILVA, L. M. S. Impactos do crédito produtivo nas noções locais de} sustentabilidade em agroecossistemas familiares no território sudeste do Pará. 2008. Tese (Doutorado em agronomia) - Programa de Pós-Graduação em Agronomia, Universidade de Pelotas, Pelotas-RS, 2008.

SILVA, L. M. S. et al. Espaço amazônico e estado de sustentabilidade de lógicos familiares de produção: adaptações e uso do MESMIS no caso do estado do Pará. Agricultura Familiar: pesquisa, formação e desenvolvimento, Belém, v. 11, n. 1, p. 57-70, jul./dez. 2017.

SOUZA, R. T. M. et al. Avaliação de sustentabilidade de agroecossistemas familiares de base agroecológica mediante a utilização do método MESMIS numa abordagem sistêmica. Revista Brasileira de Agroecologia, Dois Vizinhos, v. 11, p. 354-366, dez. 2016.

VAN BELLEN, H. M. Indicadores de sustentabilidade: um levantamento dos principais sistemas de avaliação. Cad. EBAPE.BR, Rio de Janeiro, v. 2, n. 1, p. 01-14, mar. 2004.

VERONA, L. A. F. A real sustentabilidade dos modelos de produção da agricultura: indicadores de sustentabilidade na agricultura. Horticultura Brasileira, Brasília, DF, v. 28, p. 52-66, 2010.

VIEIRA, I. C. G. Abordagens e desafios no uso de indicadores de sustentabilidade no contexto amazônico. Ciência e Cultura, São Paulo, v. 71, n. 1 , p. 46-50, jan. 2019. 
WEISHEIMER, N. Desenvolvimento rural, capitalismo e agricultura familiar.

Olhares Sociais, Cachoeira, v. 2, p. 51-78, jan./jun. 2013. ZHIRZHÁN, A.; RAMIRO, W. Evaluación de la sustentabilidad del sistema de producción en la zona baja de la parroquia San Joaquín. 2013. Dissertação (Mestrado em Engenharia Agropecuária Industrial) - Programa de Pós-Graduação em Engenharia Agropecuária Industrial, Universidad Politécnica Salesiana, Cuenca-Equador, 2013.

Texto submetido à Revista em 09.03.2020 Aceito para publicação em 09.06.2021 